\title{
Perancangan Infografis Songket Lombok
}

\author{
Fadhli Almu'iini Ahda ${ }^{1}$, Fariz Aulia Rahman ${ }^{2}$ \\ ${ }^{1}$ Desain Komunikasi Visual, STMIKASIA \\ ${ }^{1}$ fadhlial@asia. ac. id, ${ }^{2}$ fariz. aulia@gmail.com
}

\begin{abstract}
ABSTRAK
Pulau Lombok tidak hanya memiliki keindahan alam yang menakjubkan, Pulau Lombok juga memiliki kain tenun khas daerah yang dinamakan kain songket Lombok. Namun demikian, masih banyak masyarakat luas yang belum mengetahui keberadaan songket Lombok tersebut khususnya masyarakat luar pulau Lombok. Dengan seiring berkembangnya teknologi sekarang, informasi dalam bentuk video animasi banyak diminati masyarakat luas karena tampilannya yang lebih menarik. Maka dari itu informasi kain songket Lombok berupa video infografis sangat diperlukan. Infografis adalah media yang digunakan untuk menginformasikan tentang keindahan kains ongket Lombok, dengan menggunakan infografis ini informasi akan terlihat menarik dan mudah dipahami. Observasi dilakukan langsung dipengrajin songket yaitu di desa Sukerare dan desa Sade. Melakukan wawancara langsung ke pengerajin juga berperan penting untuk mengetahui data apa saja yang dibutuhkan. Perancangan video animasi infografis ini menggunakan teknik motion graphic. Perancangan infografis ini bertujuan untuk memberikan informasi tentang kain songket Lombok kepada wisatawan lokal maupun mancanegara. Perancangan konsep mengambil tema infografis. Infografis ini menggunakan gambar, foto, backsound dan juga text sebagai pendukung. Video animasi ini dirancang menggunakan aplikasi Adobe Ilustrator CS6 untuk membuat sketsa menjadi bentuk digital, Adobe After Effect CS6 untuk membuat pergerakan animasi, Adobe Audition CS6 untuk memberi dubbing. Hasil dari pengujian kepada 33 responden sebagai sampel adalah77. 5\%.
\end{abstract}

KataKunci: Animasi, Infografis, Motion Graphic, Songket Lombok

\section{ABSTRACT}

Lombok Island notonlyh as a stunning natural beauty, Lombok Island also has a special woven cloth area called the songket Lombok. However, there are still many people who do not know the existence of Lombok songket especially the people outside the island of Lombok. But as the development of technology now, information in the form of animated video muchin demand by thepublic because it looks more interesting. There fore information of Lombok songket clothin the form of info graphic video is needed. Infog raphics is a medium thatis used to inform about the beauty of Lombok songket cloth, by using this infographic information will look interesting and easy to understand. The observations were conducted directly in the songket craftsmen in Sukerare and Sade villages. Conducting interviews directly to the craft smanalso playsan important role to know what data are needed. The design of this infographic animation videousing motion graphic technique. This infographic design aims to provide information about Lombok songket clothtolocal and foreign tourists. The design of the concept takes the theme of infographics. This infographic uses images, photos, backsound and also text as support. This animated video was designed using Adobe Illustrator CS6 application to sketch into digital form, Adobe After Effect CS6 to create animated movement, Adobe Audition CS6 to give dubbing. Results from the testto 33 respondents as sampleswere 77. 5\%.

Keywords: Animation, Infographics, Motion Graphic, Songket Lombok

\section{PENDAHULUAN}

Pulau Lombok adalah sebuah pulau yang berada disebelah timur Pulau Bali, Pulau Lombok sering disebut-sebut memiliki kemiripan dengan pulau Bali, baik dari segi keindahaan alam maupun senibudaya. Selain keindahan alam, Pulau Lombok juga memiliki kain tenun khas daerah yang dinamakan kain songket Lombok. Warna-warna cerah dengan motif unik adalah bagian dari ciri khasnya.

Songket Lombok berbeda dengan tenun-tenun songket yang ditemukan didaerah lain di Indonesia, terutama songket-songket yang berasal dari Melayu yang ditemukan di daerah Sumatera dan Kalimantan, songket Lombok tidak menggunakan benang emas atau 
perak tetapi sebagai gantinya menggunakan benang katun warna-warni sehingga memberi tampilan yang lebih semarak. Namun demikian, masih banyak masyarakat luas yang belum mengetahui keberadaan songket Lombok tersebut khususnya masyarakat luar Pulau Lombok. Namun seiring berkembangnya teknologi sekarang, informasi dalam bentuk infografis banyak diminati masyarakat luas karena tampilannya yang lebih menarik. Maka dari itu informasi kain songket Lombok berupa infografis sangat diperlukan.

Infografis adalah sebuah media untuk menginformasikan tentang keindahan kain songket Lombok. Infografis ini akan dirancang dengan objek-objek 2 dimensi, dengan menggunakan infografis ini informasi akan lebih mudah dipahami. selain itu perancangan infografis ini lebih hemat dari segi biaya. Infografis ini dirancang dengan teknik motion graphic.

Motion graphic merupakan teknik yang akan digunakan untuk menginformasikan tentang kain songket Lombok. Mengingat saat ini merupakan era digital, akan efektif bila informasi yang akan kita sampaikan juga berbentuk digital, karena informasi digital dapat diakses dengan mudah diera yang serba digital seperti sekarang ini. Biografi yang berupa motion graphic, dapat menarik perhatian parawisatawan. Dengan masalah diatas maka penulis mencoba merancang sebuah infografis sebagai media informasi untuk mengetahui kain songket yang ada di Pulau Lombok

\section{PEMBAHASAN}

Berdasarkan tujuan perancangan yaitu menginformasikan kain songket Lombok kepada wisatawan, maka perancangan video animasi infografis dengan menggunakan teknik motion graphic ini menjadi alternatif yang dipilih sebagai medianya karena infografis ini informasi akan terlihat lebih menarik dan mudah dipahami. Didalam tahapan ini perancangan konsep mengambil tema video infografis. Untuk menguatkan konsep tersebut, video infografis ini menggunakan gambar, foto, backsound dan juga text untuk menjelaskan macam-macam motif songket yang ada di pulau Lombok. Story line dijelaskan dalam bentuk scene yang terdiri dari sembilan scene, seperti yang terdapat pada tabel 1.

Tabel 1. Storyline

\begin{tabular}{|c|l|}
\hline Scene & \multicolumn{1}{|c|}{ Keterangan } \\
\hline Scene 1 & Opening luas \\
\hline Scene 2 & $\begin{array}{l}\text { Kemudian, muncul peta indonesia yang menjelaskan luan } \\
\text { wilayah indonesia. }\end{array}$ \\
\hline Scene 3 & Selanjutnya, muncul peta pulauLombok. \\
\hline Scene 4 & $\begin{array}{l}\text { Kemudian muncul gambar dan text yang menjelaskan } \\
\text { kalau di Lombok tidak hanya memiliki keindahaan alam } \\
\text { tetapi juga memiliki kain songket. }\end{array}$ \\
\hline Scene 5 & $\begin{array}{l}\text { Muncul frame keterangan perbedaan songket Lombok dan } \\
\text { Melayu }\end{array}$ \\
\hline Scene 6 & $\begin{array}{l}\text { Selanjutnya muncul foto dan text yang menjelaskan } \\
\text { perbedaan songket Lombok dan songket Melayu. }\end{array}$ \\
\hline Scene 7 & $\begin{array}{l}\text { Muncul kembali frame keterangan macam-macam motif } \\
\text { songket. }\end{array}$ \\
\hline
\end{tabular}




\begin{tabular}{|c|l|}
\hline Scene & \multicolumn{1}{|c|}{ Keterangan } \\
\hline Scene 8 & $\begin{array}{l}\text { Memunculkan foto-foto motif kain apa saja yang ada } \\
\text { dipulau Lombok. }\end{array}$ \\
\hline Scene 9 & Muncul frame keterangan cara pembuatan songket. \\
\hline Scene 10 & $\begin{array}{l}\text { Selanjutnya muncul karakter wanita yang menjelaskan } \\
\text { teknik pembuatan benang hingga menjadi songket. }\end{array}$ \\
\hline Scene 11 & Ajakan untuk melestarikan kainsongket. \\
\hline Scene 12 & Closing \\
\hline
\end{tabular}

Pembuatan story board ini bertujuan sebagai dasar sebelum membuat media informasi berbasis infografis animasi, sehingga tidak terjadi pengulangan dalam pembuatannya. Sebelum proses pengambilan foto dan editing, membuat story board yang merupakan kolom teks, audio dan visualisasi dengan keterangan mengenai konten dan visuallisasi yang digunakan untuk produksi.

Tabel 2. Story board

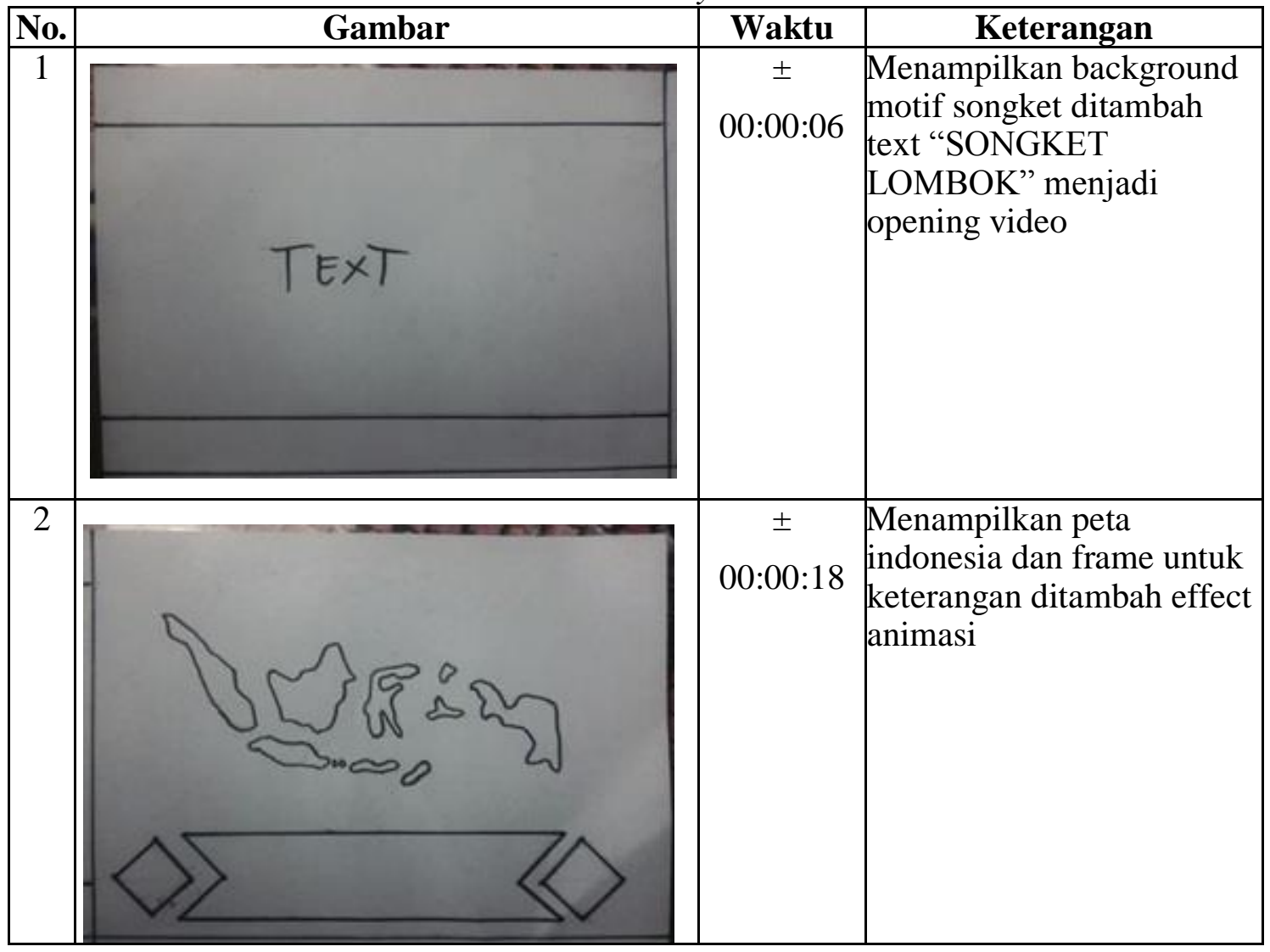




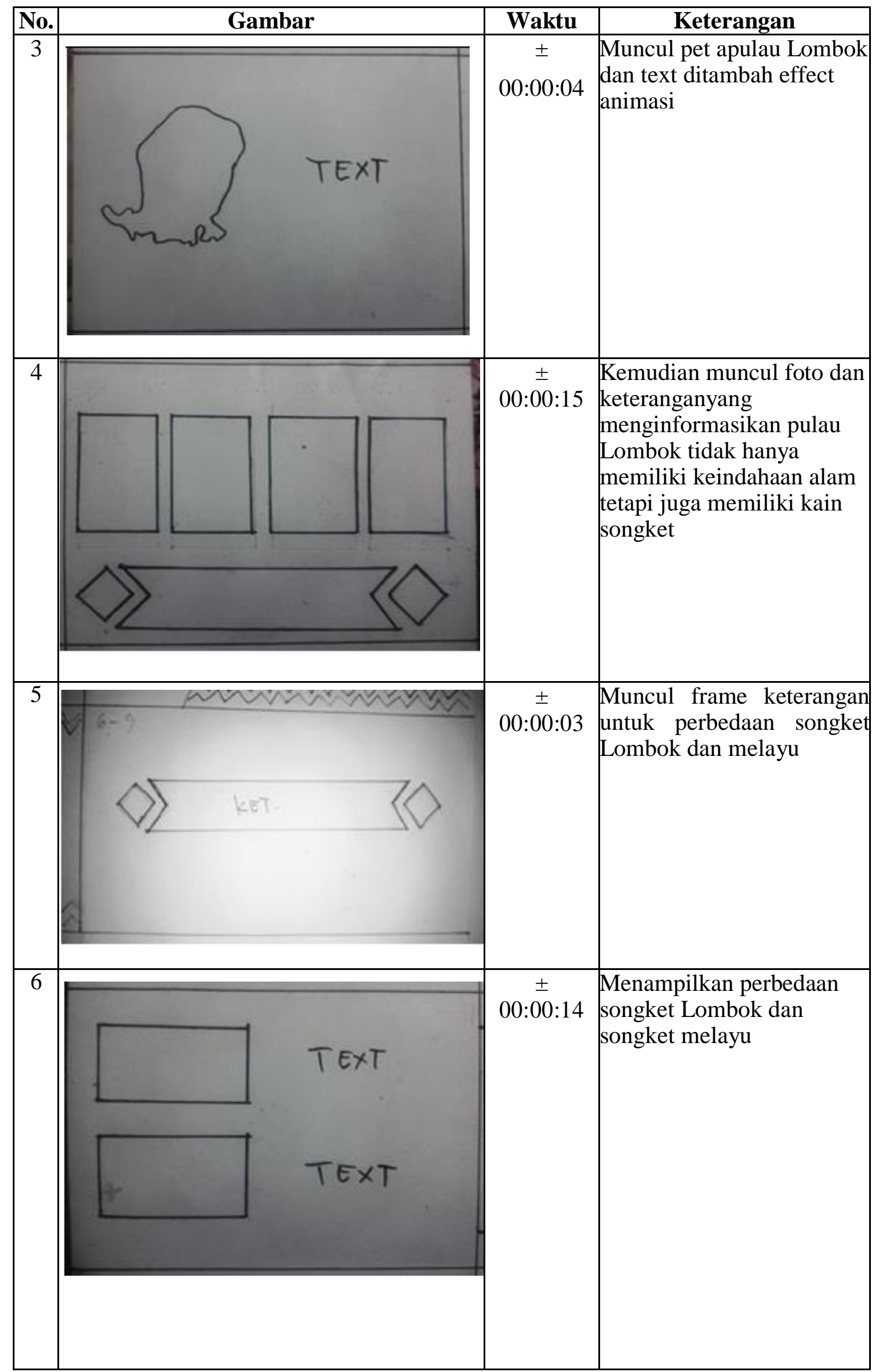




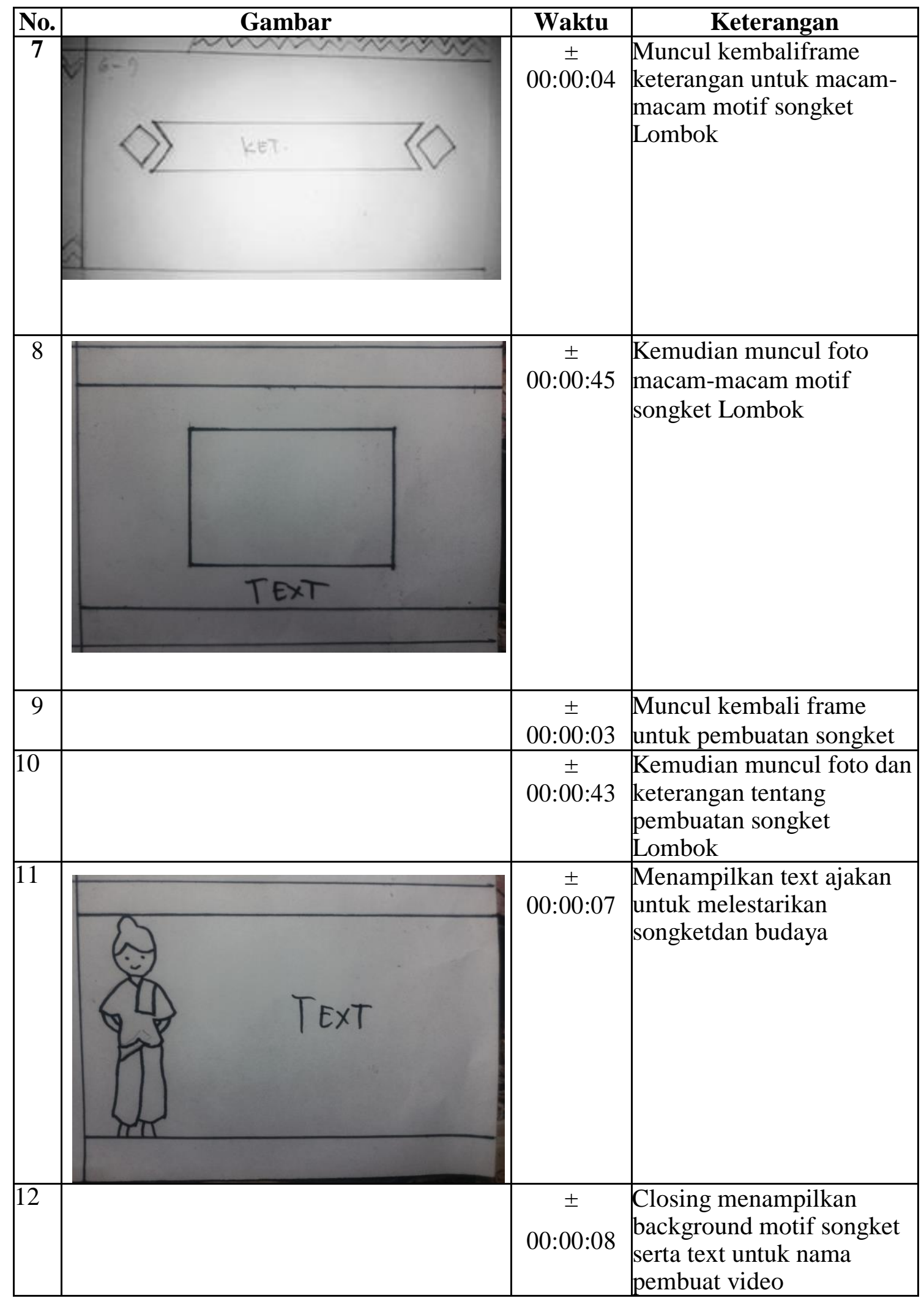

Setelah tahap tracing selesai, diperlukan tahap editing dan coloring untuk memberikan warna yang sesuai dengan objek yang dibuat agar hasil menjadi lebih nyata dan menarik. Untuk memberikan warna pada setiap objek bisa dilakukan melalui Proses 
editor. Proses editor berfungsi untuk mengatur semua proses pewarnaan dan nantinya dapat mempermudah dalam proses Animasi

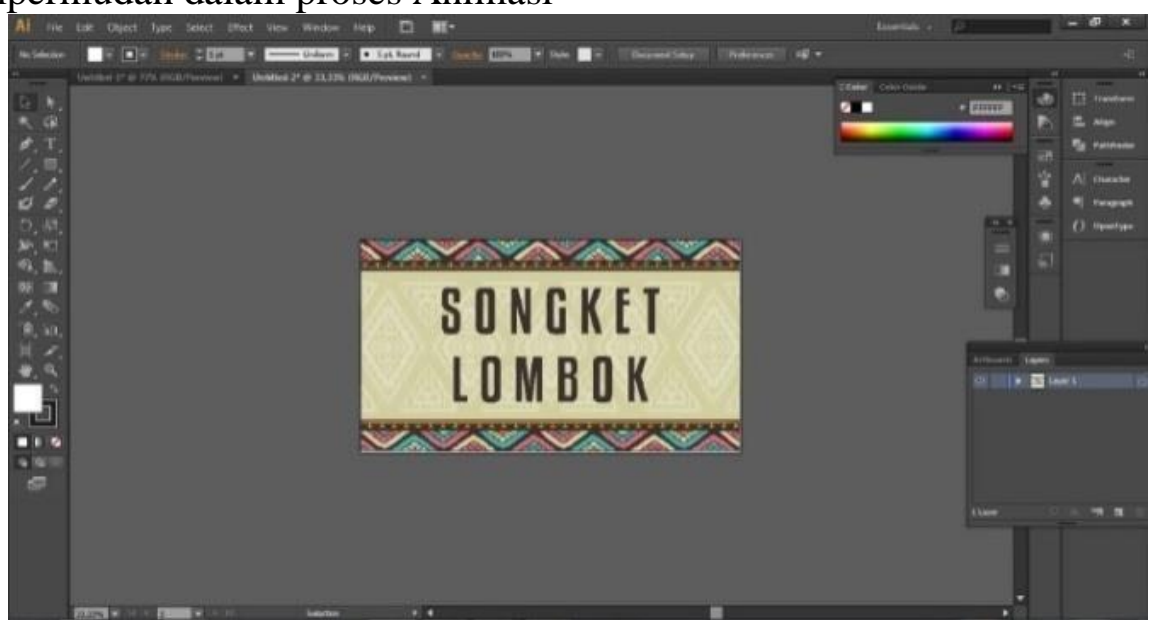

Gambar 1. Proses Coloring Scene 1

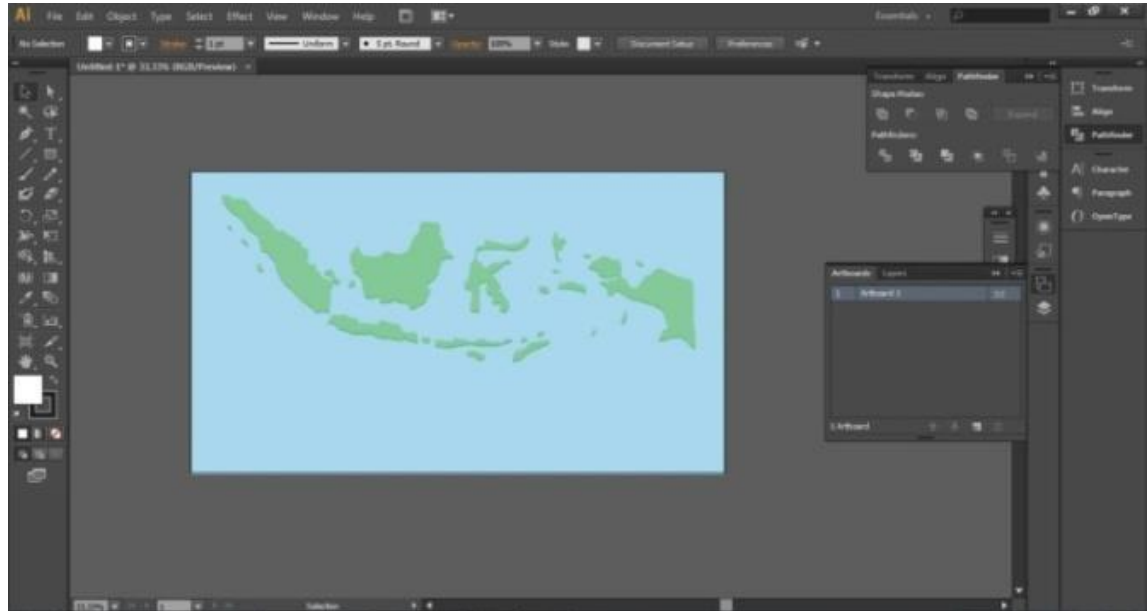

Gambar 2. Proses Coloring Scene 2

Proses editing pewarnaan dengan Pen tool dan Magic won untuk menyeleksi hasil gambar dan pewarnaan, Sedangkan pen tool untuk path yang tidak rata pada garis pensil. Dan terdapat layer untuk mengatur hasil path dalam pewarnaan. Dan dapat diatur untuk Forward dan Back forwad.

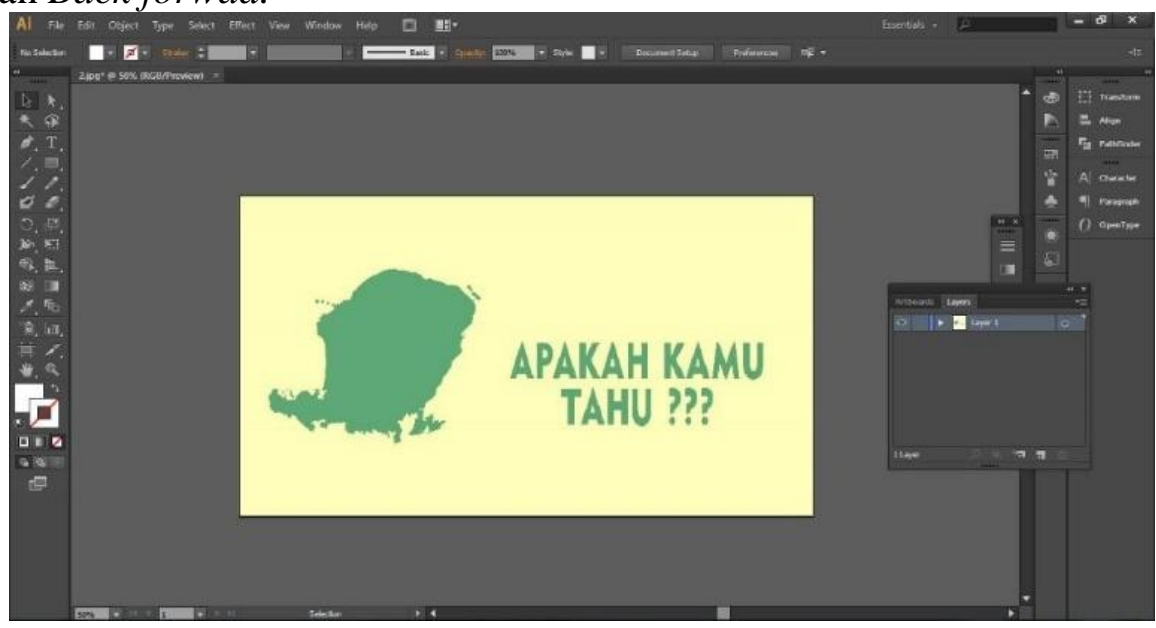

Gambar 3. Proses Coloring Scene 3 menampilkan peta pulau Lombok 


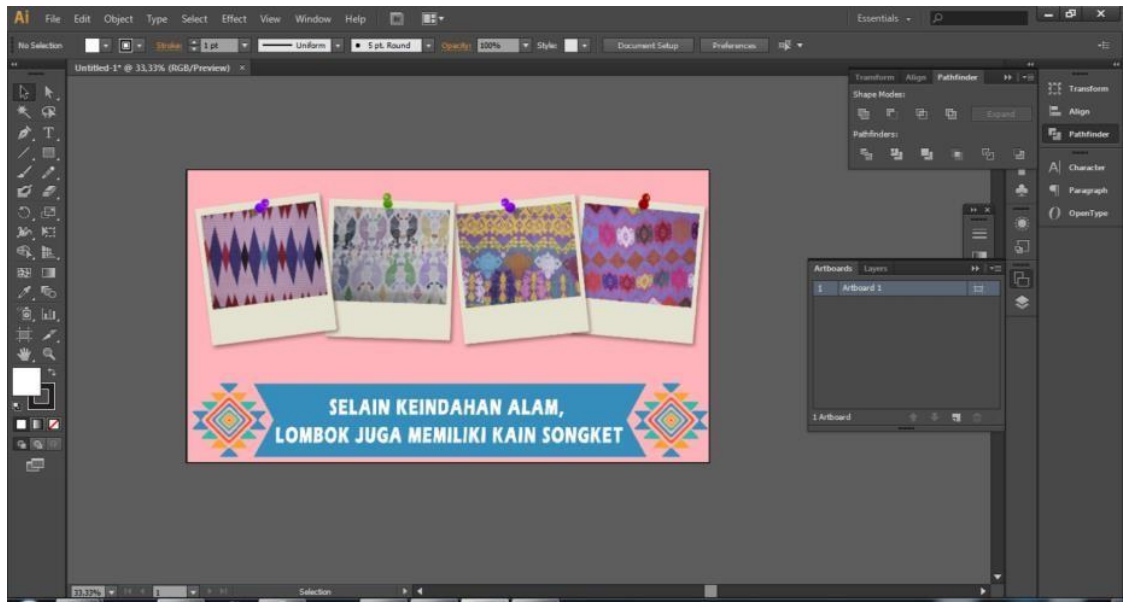

Gambar 4. Lombok tidak hanya memiliki keindahan alam tetapi juga kain songket

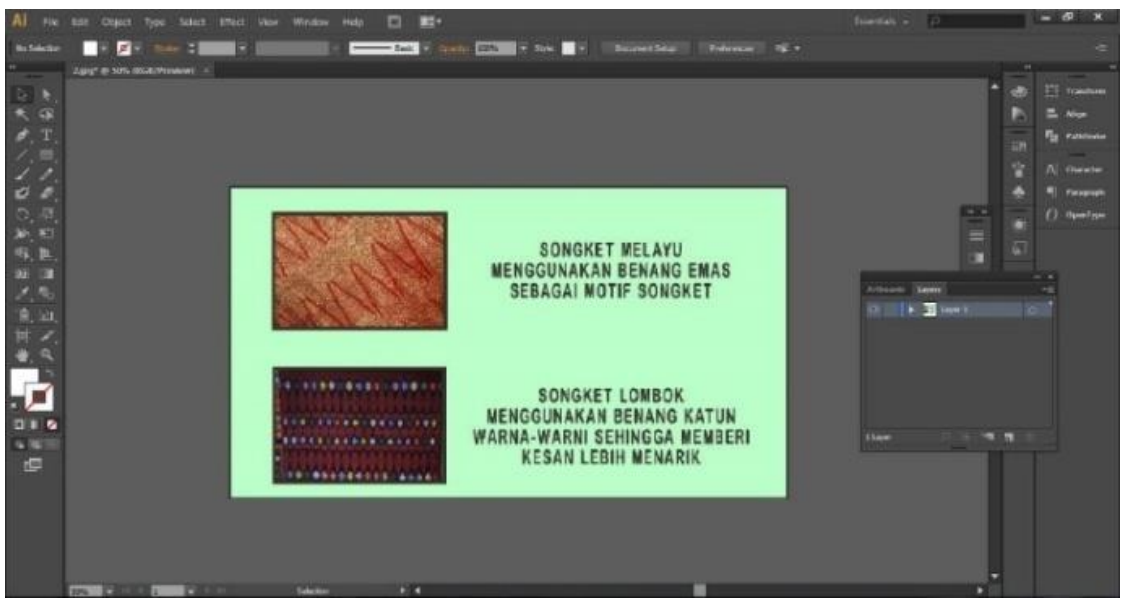

Gambar 5. Beda Songket Lombok dengan Songket Daerah lain

Pada scene 6 ini text keterangan perbedaan songket lombok dan melayu diberi effect animasi menggunakan animation composer, sedangkan untuk text menggunakan effect typewriter.

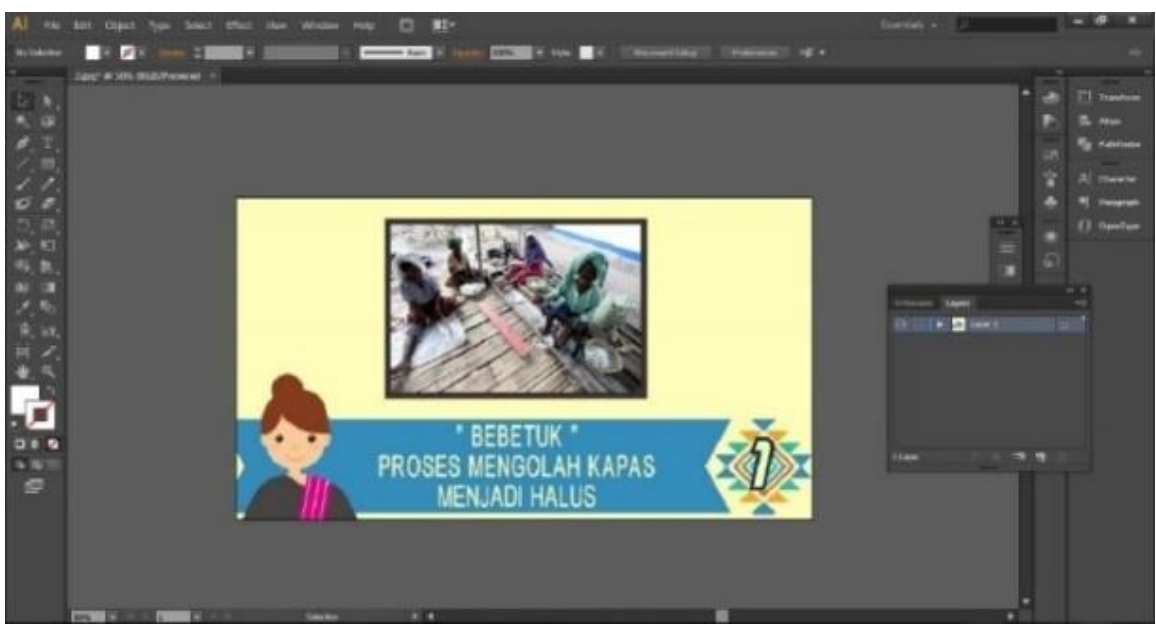

Gambar 6. Proses pembuatan Songket 


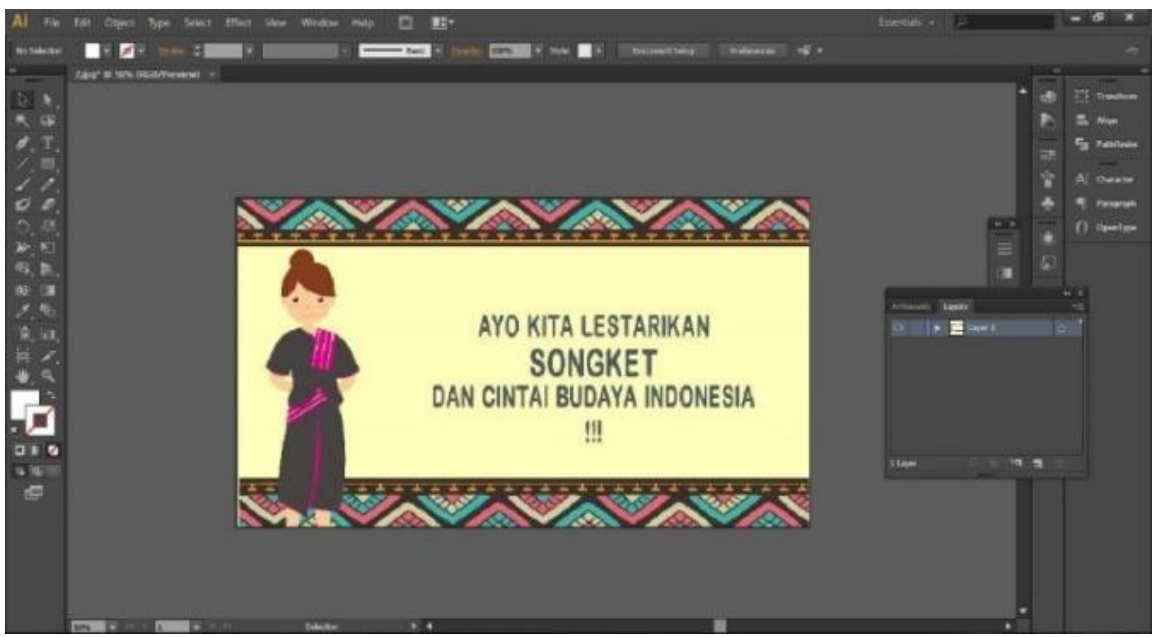

Gambar 7. Ajakan Untuk Melestarikan Songket dan budaya

Proses Pengisian Suara (DUBBING) Pada Adobe Audition Dalam proses ini adalah pengisian suara atau dubbing agar informasi yang disampaikan kepada Audience lebih jelas dan informatif.

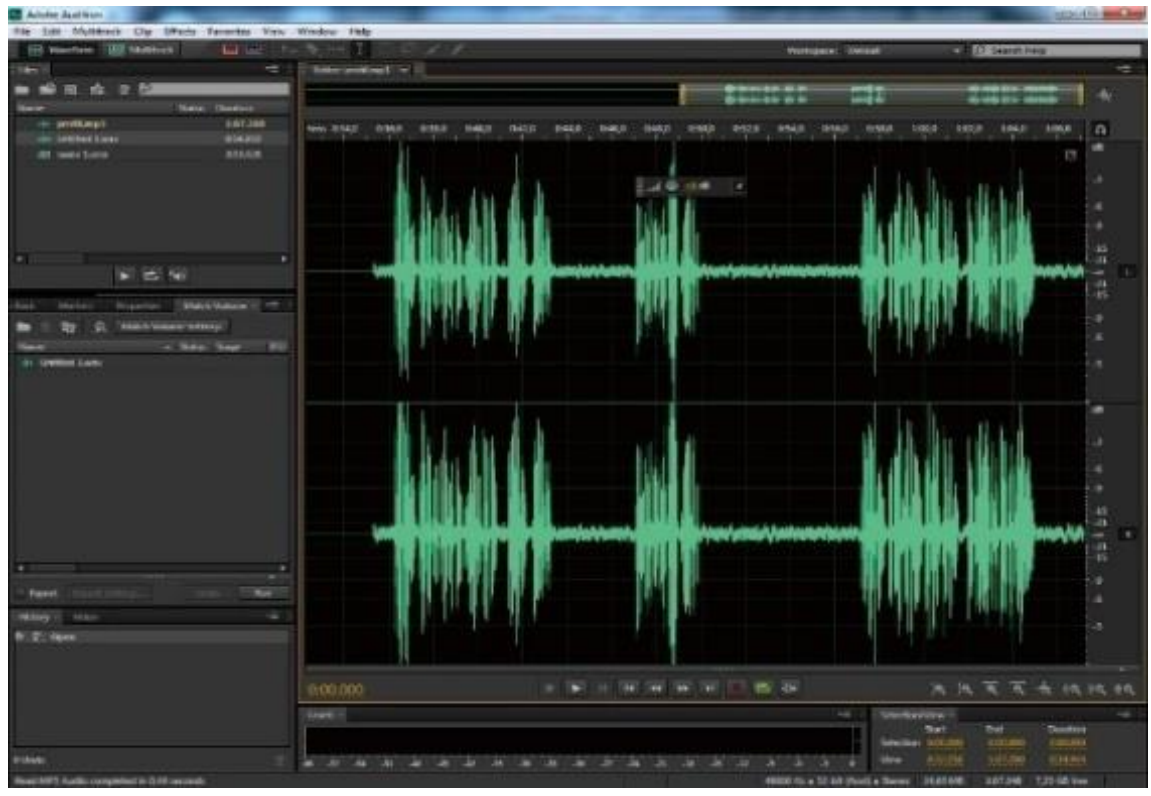

Gambar 8. Tampilan proses rekaman pada adobe audition

Untuk memastikan suatu project atau media berjalan dengan baik dan sebagaimana mestinya, tahapan akhir adalah proses pengujian. Pengujian dilakukan dengan memberikan kuisioner secara langsung kepada responden untuk menjadi sampel penelitian.

Penulis menggunakan lembar kuisoner dengan mengajukan7 pertanyaan. Cara pengukurannya yaitu dengan menghadapkan subjek (masyarakat yang diuji) pada sejumlah pernyataan, kemudian mereka diminta untuk memilih jawaban mulai dari Sangat Baik, Baik, Cukup, Kurang. Selama 3hari telah terkumpu 133 responden dengan jawaban bervariasi. Dari total 33 responden didapatlah tanggapan baik yaitu dengan nilai presentase 77,5 
Video animasi infografis ini merupakan media yang efektif untuk memperkenalkan kain songket kepada wisatawan lokal maupun mancanegara. Melalui Media informasi kain songket ini, parawisatawan lebih dapat memahami lagi tentang kain songket yang adadi pulau Lombok. Desain tampilan dari program media informasi ini sangat mudah dipahami, dan disertai animasi sehingga media informasi ini dapat dipahami lebih mudah. PembuatanVideo informasi ini dibatasi pada informasi terkait jenis motif songket yang ada di pulau Lombok. Dari 7 pertanyaan publik menanggapi cukup baik tentang produk yang dihasilkan dengan persentase $77.5 \%$.

\section{DAFTAR PUSTAKA}

Chandra. 2005. Membuat Berbagai DVD-Video Dengan Ulead Studio 9, Bandung: Elex Media Komputindo

Curran, Steve. 2000. Motion Graphics: Graphic Design for Broad cast and Film: Rockport Hendratman, Hendi. 2008. Tips and Trix Computer Graphic Design. Bandung: Informatika Hendratman, Hendi. 2010. Computer Graphic Design. Bandung: Informatika.

Krasner, Jon. 2008. Motion Graphic Design Applied Historic and Aesthetics. Oxford: Elsevier

Munir. 2013. Multimedia: Konsep \& Aplikasi dalam Pendidikan. Bandung. Alfabeta.

Nazir, Mohammad. 1988. Metode Penelitian. Jakarta: Ghalia Indonesia:

Nugraha, Ali, \& Rachmawati, Yeni. 2008. Metode pengembangan sosial emosional, Jakarta: Universitas Terbuka.

Pujirianto. 2005. Desain Grafis Komputer (Teori Grafis Komputer) Yogyakarta: Andi

Purnamawati, Eldarni. 2001 Media Pembelajaran. Jakarta: CV. Rajawali

Sadjiman, Ebdi Sanyoto. 2005. Dasar-Dasar Tata Rupa dan Desain (Nirmana) Yogyakarta: Arti Sari Intaran.

Sihombing. 2001. Pengenalan Desain Grafis. Jakarta: Gramedia Pustaka Utama

Subakti. 2010. Majalah Bisnis Komputer. Jakarta: AKY Press

Sugiyono. 2011. Metode penelitian pendidikan. Bandung: Alfabeta.

Susanto, Mikke. 2002. Kumpulan Istilah Seni Rupa. Yogyakarta: Kanisius.

Wong, Wucius. 1995. Beberapa Asas Merancang Dwimatra. Bandung: ITB. 